\title{
Resistance trends in gram-negative bacteria: surveillance results from two Mexican hospitals, 2005-2010
}

\author{
Rayo Morfin-Otero ${ }^{1,2^{*}}$, Juan Carlos Tinoco-Favila ${ }^{3}$, Helio S Sader ${ }^{4}$, Lorena Salcido-Gutierrez ${ }^{3}$, \\ Hector Raul Perez-Gomez ${ }^{1,2}$, Esteban Gonzalez-Diaz ${ }^{1,2}$, Luis Petersen ${ }^{1}$ and Eduardo Rodriguez-Noriega ${ }^{1,2}$
}

\begin{abstract}
Background: Hospital-acquired infections caused by multiresistant gram-negative bacteria are difficult to treat and cause high rates of morbidity and mortality. The analysis of antimicrobial resistance trends of gram-negative pathogens isolated from hospital-acquired infections is important for the development of antimicrobial stewardship programs. The information obtained from antimicrobial resistant programs from two hospitals from Mexico will be helpful in the selection of empiric therapy for hospital-acquired gram-negative infections.

Findings: Two thousand one hundred thirty two gram-negative bacteria collected between January 2005 and December 2010 from hospital-acquired infections occurring in two teaching hospitals in Mexico were evaluated. Escherichia coli was the most frequently isolated gram-negative bacteria, with $>50 \%$ of strains resistant to ciprofloxacin and levofloxacin. Klebsiella spp. showed resistance rates similar to Escherichia coli for ceftazidime (33.1\% vs 33.2\%), but exhibited lower rates for levofloxacin (18.2\% vs 56\%). Of the samples collected for the third most common gram-negative bacteria, Pseudomonas aeruginosa, $>12.8 \%$ were resistant to the carbapenems, imipenem and meropenem. The highest overall resistance was found in Acinetobacter spp. Enterobacter spp. showed high susceptibility to carbapenems.

Conclusions: E. coli was the most common nosocomial gram-negative bacilli isolated in this study and was found to have the second-highest resistance to fluoroquinolones ( $>57.9 \%$, after Acinetobacter spp. 81.2\%). This finding represents a disturbing development in a common nosocomial and community pathogen.
\end{abstract}

Keywords: Bacterial, Resistance, Gram negative, Nosocomial, Infections

\section{Findings}

Rational for the surveillance of bacterial resistance trends Gram-negative infections are responsible for a large portion of device-associated infections, procedure-associated infections, and healthcare-associated infections [1]. Recent data from the National Healthcare Safety Network indicate that gram-negative bacteria are responsible for more than $30 \%$ of hospital-acquired infections and more than $40 \%$ of infections in patients in intensive care units $[2,3]$. Hospital-acquired infections caused by gram-negative

\footnotetext{
* Correspondence: rayomorfin@gmail.com

${ }^{1}$ Instituto de Patología Infecciosa y Experimental, Centro Universitario

Ciencias de la Salud, Universidad de Guadalajara, Calle Hospital 308, Colonia

El Retiro, CP 44280, Guadalajara, Jalisco, Mexico

${ }^{2}$ Infectología, Microbiología, Hospital Civil de Guadalajara, Fray Antonio

Alcalde, Guadalajara, Mexico

Full list of author information is available at the end of the article
}

bacteria are difficult to manage, due to the increasingly varied resistance mechanisms that these bacteria can develop [4,5].The continuous surveillance of antibiotic resistance trends in bacteria isolated from hospital-acquired infections is essential for the selection of adequate initial empiric therapy [6,7].The laboratory-based antibiograms is efficacious as a guide for the rational selection of antimicrobial therapy, and to alert healthcare providers to the presence of unusual or emerging antimicrobial mechanisms [8]. The evaluation of antimicrobial resistance in gram-negative bacterial strains in two Mexican hospitals during 2005-2010 is presented.

\section{Methods}

The participating hospitals in this study are similar in their patient characteristics. The Hospital Civil de

\section{Biomed Central}


Guadalajara Fray Antonio Alcalde is a 1,000 bed tertiary care teaching hospital located in the city of Guadalajara, the second largest city in Mexico. The Hospital General de Durango is a 300-bed teaching hospital located in the city of Durango, which is the capital of the state of Durango in Mexico.

All isolates were identified at the participating institution by routine methodologies that are in use at each laboratory. Upon receipt at the central monitor (JMI Laboratories, North Liberty, IA, USA), isolates were subcultured to ensure viability and purity. Confirmation of species identification was performed with the Vitek system (bioMérieux Vitek, St Louis, MO) $[9,10]$.

A total of 2132 gram-negative bacteria were collected between January 2005 and December 2010 and were analyzed in the present study. The organisms were consecutively collected according to the types of infection, which primarily included bloodstream infections, skin and skin structure infections, and pneumonia in hospitalized patients. The organisms evaluated in this study included E. coli (563 strains), Klebsiella spp. (329 strains), P. aeruginosa (404 strains), Acinetobacter spp. (362 strains) and Enterobacter spp. (214 strains).

Included among 260 other gram-negatives collected were Citrobacter spp. (32 strains, including 26 Citrobacter freundii), Proteus spp. (34 strains, including 29 Proteus mirabilis), Serratia spp. (64 strains, including 61 Serratia marcescens), Stenotrophomonas maltophilia (37 strains), Pseudomonas fluorescens (10 strains), Salmonella spp. (24 strains, including 2 Salmonella cholerasuis, 1 Salmonella paratyphi), and 59 (<3 isolates) other gram-negatives.

Antimicrobial susceptibility testing was performed using the broth microdilution method following the recommendations of the Clinical and Laboratory Standards Institute, M07-A8 [11].Antimicrobial powders were obtained from the respective manufacturers, and microdilution plates were prepared by ThermoFisher Scientific (formerly TREK Diagnostics; Cleveland, $\mathrm{OH}$, USA). The susceptibility results were interpreted according to the Clinical Laboratory Standards Institute document M100-S21 [12-16].

E. coli and Klebsiella pneumoniae isolates with MIC values of $\geq 2 \mu \mathrm{g} / \mathrm{mL}$ for aztreonam and/or ceftazidime and/or ceftriaxone were considered extended spectrum betalactamases (ESBL) phenotypes[17,18]. Quality control was established by testing E. coli ATCC 25922, P. aeruginosa ATCC 27853, Staphylococcus aureus ATCC 29213, and Streptococcus pneumoniae ATCC 49619.

Linear trend analysis for resistance trend over time was performed using SPSS statistical software, version 17.0 .

\section{Results}

The most common gram-negative isolate was $E$. coli (Table 1). Of the E. coli strains, $33.2 \%$ were resistant to ceftazidime; $>55 \%$ were resistant to the two fluoroquinolones tested, ciprofloxacin and levofloxacin; and 31.9\% were resistant to gentamicin (Table 1). The E. coli isolates were consistently susceptible to carbapenems and amikacin, (100.0\% and 95.7\%, respectively), while piperacillin/tazobactam was active against $83.1 \%$ of strains at the susceptible breakpoint (Table 1).

Klebsiella spp. showed high resistant rates to ceftazidime (33.1\% compared to $24.0 \%$ in $P$. aeruginosa), but relatively low resistance to fluoroquinolones $(\leq 18.2 \%$ vs. $>50 \%$ in E. coli), more resistant to amikacin (13.1\% vs. $0.4 \%$ in $E$. coli), and had similar susceptibility rates to the carbapenems as E. coli, $\geq 98.4 \%$ (Table 2).

Of the isolated gram-negative bacteria, Pseudomonas aeruginosa was the third most common organism after E. coli and Klebsiella spp. (Table 3). P. aeruginosa exhibited high resistance rates to the two carbapenems tested, $17.8 \%$ of the isolates were resistant to imipemen and $12.8 \%$ were resistant to meropenem (Table 3 ).

Acinetobacter spp, the fourth most common gramnegative bacilli isolated during this study, was the most resistant to the antimicrobials tested (Table 4). More than $60 \%$ of the Acinetobacter spp. isolates were resistant to all antibiotics tested, except imipenem (36.4\% resistance), meropenem (37.4\% resistance) and colistin / polymyxin B, 1.5 / 1.4\% resistance (Table 4 ).

Table 1 Comparison of the in vitro activities of selected antimicrobial agents tested against Escherichia coli (563 strains)

\begin{tabular}{|c|c|c|c|c|}
\hline Antimicrobial agent & $\mathrm{MIC}_{50}$ & $\mathrm{MIC}_{90}$ & Range & $\begin{array}{l}\text { \% susceptible/ } \\
\text { resistant }^{\mathrm{a}}\end{array}$ \\
\hline Cefuroxime & 8 & $>16$ & $\leq 2->16$ & $55.2 / 43.2$ \\
\hline Cefoxitin & 4 & $>16$ & $\leq 4->16$ & 74.9 / 13.7 \\
\hline Ceftriaxone & $\leq 0.25$ & $>32$ & $\leq 0.25->32$ & $56.8 / 41.7$ \\
\hline Ceftazidime & $\leq 1$ & $>16$ & $\leq 1->16$ & $61.6 / 33.2$ \\
\hline Cefepime & 0.25 & $>16$ & $\leq 0.12->16$ & 71.4 / 19.9 \\
\hline Piperacillin/tazobactam & 4 & 32 & $\leq 0.5->64$ & $83.1 / 3.9$ \\
\hline Imipenem & $\leq 0.12$ & 0.25 & $\leq 0.12-1$ & $100.0 / 0.0$ \\
\hline Meropenem & $\leq 0.12$ & $\leq 0.12$ & $\leq 0.12-0.5$ & $100.0 / 0.0$ \\
\hline Ciprofloxacin & $>4$ & $>4$ & $\leq 0.03->4$ & $41.7 / 57.9$ \\
\hline Levofloxacin & $>4$ & $>4$ & $\leq 0.5->4$ & 41.7 / 56.7 \\
\hline Gentamicin & $\leq 2$ & $>8$ & $\leq 2->8$ & $67.1 / 31.9$ \\
\hline Amikacin & $\leq 4$ & 8 & $\leq 4->32$ & $95.7 / 0.4$ \\
\hline PolymyxinB ${ }^{b}$ & $\leq 0.5$ & $\leq 0.5$ & $\leq 0.5-1$ & $100 / 0.0$ \\
\hline Colistin $^{b}$ & $\leq 0.5$ & $\leq 0.5$ & $\leq 0.5-2$ & $99.8 / 0.2$ \\
\hline
\end{tabular}

${ }^{a}$ Criteria as published by the CLSI [16].

b Pseudomonas aeruginosa breakpoints. 
Table 2 Comparison of the in vitro activities of selected antimicrobial agents tested against Klebsiellaspp. ${ }^{a}$ (329 strains)

\begin{tabular}{|c|c|c|c|c|}
\hline Antimicrobial agent & $\mathrm{MIC}_{50}$ & $\mathrm{MIC}_{90}$ & Range & $\begin{array}{l}\text { \% susceptible/ } \\
\text { resistant }^{b}\end{array}$ \\
\hline Cefuroxime & 4 & $>16$ & $\leq 2->16$ & $62.3 / 32.2$ \\
\hline Cefoxitin & $\leq 4$ & $>16$ & $\leq 4->16$ & $82.6 / 11.8$ \\
\hline Ceftriaxone & $\leq 0.25$ & 32 & $\leq 0.25->32$ & $63.8 / 35.2$ \\
\hline Ceftazidime & $\leq 1$ & $>16$ & $\leq 1->16$ & 66.8 / 33.1 \\
\hline Cefepime & $\leq 0.12$ & 8 & $\leq 0.12->16$ & $92.7 / 4.5$ \\
\hline Piperacillin/tazobactam & 2 & $>64$ & $\leq 0.5->64$ & 79.3 / 11.2 \\
\hline Imipenem & 0.25 & 0.5 & $\leq 0.12->8$ & $98.4 / 1.2$ \\
\hline Meropenem & $\leq 0.12$ & 0.25 & $\leq 0.12->8$ & $98.4 / 0.9$ \\
\hline Ciprofloxacin & $\leq 0.03$ & $>4$ & $\leq 0.03->4$ & 80.8 / 18.2 \\
\hline Levofloxacin & $\leq 0.5$ & $>4$ & $\leq 0.5->4$ & $82.3 / 15.8$ \\
\hline Gentamicin & $\leq 2$ & $>8$ & $\leq 2->8$ & 82.6 / 14.5 \\
\hline Amikacin & 2 & $>32$ & $\leq 4->32$ & 84.1 / 13.1 \\
\hline PolymyxinB & $\leq 0.5$ & $\leq 0.5$ & $\leq 0.5->4$ & 99.2 / 0.6 \\
\hline Colistin & $\leq 0.5$ & $\leq 0.5$ & $\leq 0.5->4$ & $99.5 / 0.4$ \\
\hline
\end{tabular}

${ }^{a}$ Includes: Klebsiellaoxytoca (36 strains) Klebsiellapneumoniae (291 strains), Klebsiellaornithinolytica (1 strain) and unspeciated Klebsiella (1 strain).

${ }^{\mathrm{b}}$ Criteria as published by the CLSI [16].

c Pseudomonas aeruginosa breakpoints.

Enterobacter spp., the fifth most frequently isolated gram-negative bacilli, had a different resistance pattern than the other gram-negative bacilli tested (Table 5). All (100.0\%) Enterobacter spp. tested were susceptible to imipenem and meropenem. Only $3.7 \%$ were resistant to cefepime, $26.1 \%$ were resistant to piperacillin/tazobactam, $14.0 \%$ were resistant to ciprofloxacin, and $12.6 \%$ were resistant to levofloxacin (Table 5).

Table 3 Comparison of the in vitro activities of selected antimicrobial agents tested against Pseudomonas aeruginosa (404 strains)

\begin{tabular}{lllll}
\hline Antimicrobial agent & MIC $_{\mathbf{5 0}}$ & $\mathbf{M I C}_{\mathbf{9 0}}$ & Range & $\begin{array}{l}\text { \% susceptible / } \\
\text { resistant }^{\mathbf{a}}\end{array}$ \\
\hline Ceftazidime & 2 & $>16$ & $\leq 1->16$ & $71.7 / 24.0$ \\
Cefepime & 4 & 16 & $0.5->16$ & $77.9 / 9.9$ \\
Piperacillin/tazobactam & 8 & $>64$ & $\leq 0.5->64$ & $68.8 / 15.5$ \\
Imipenem & 2 & $>8$ & $\leq 0.12->8$ & $74.9 / 17.8$ \\
Meropenem & 0.5 & $>8$ & $\leq 0.12->8$ & $76.4 / 12.8$ \\
Ciprofloxacin & 0.25 & $>4$ & $\leq 0.03->4$ & $75.2 / 20.0$ \\
Levofloxacin & $\leq 0.5$ & $>4$ & $\leq 0.5->4$ & $74.2 / 24.0$ \\
Gentamicin & $\leq 2$ & $>8$ & $\leq 2->8$ & $64.1 / 31.9$ \\
Amikacin & 4 & $>32$ & $\leq 4->32$ & $70.3 / 23.7$ \\
PolymyxinB & 1 & 1 & $\leq 0.5-2$ & $100.0 / 0.0$ \\
Colistin & 1 & 2 & $\leq 0.5-2$ & $100.0 / 0.0$ \\
\hline
\end{tabular}

${ }^{a}$ Criteria as published by the CLSI [16].

${ }^{\mathrm{b}}$ Criteria published by the CLSI [15].
Table 4 Comparison of the in vitro activities of selected antimicrobial agents tested against Acinetobacte spp. ${ }^{a}$ (362 strains)

\begin{tabular}{lllll}
\hline Antimicrobial agent & MIC $_{\mathbf{5 0}}$ & $\mathbf{M I C}_{\mathbf{9 0}}$ & Range & $\begin{array}{l}\text { \% susceptible / } \\
\text { resistant }^{\mathbf{b}}\end{array}$ \\
\hline Ceftazidime & $>16$ & $>32$ & $\leq 1->16$ & $17.1 / 74.3$ \\
Cefepime & 16 & $>16$ & $\leq 0.12->16$ & $28.7 / 49.4$ \\
Piperacillin / tazobactam & $>64$ & $>64$ & $\leq 0.5->64$ & $16.3 / 77.9$ \\
Imipenem & 4 & $>8$ & $\leq 0.12->8$ & $52.3 / 36.4$ \\
Meropenem & 4 & $>8$ & $\leq 0.12->8$ & $52.3 / 37.4$ \\
Ciprofloxacin & $>4$ & $>4$ & $\leq 0.03->4$ & $18.2 / 81.2$ \\
Levofloxacin & $>4$ & $>4$ & $\leq 0.5->4$ & $18.7 / 78.1$ \\
Gentamicin & $>8$ & $>8$ & $\leq 2->8$ & $34.2 / 63.5$ \\
Amikacin & $>32$ & $>32$ & $\leq 4->32$ & $22.1 / 64.9$ \\
PolymyxinB & $\leq 0.5$ & $\leq 0.5$ & $\leq 0.5->4$ & $98.6 / 1.4$ \\
Colistin & $\leq 0.5$ & 1 & $\leq 0.5->4$ & $98.5 / 1.5$ \\
\hline
\end{tabular}

a Includes Acinetobacterbaumannii (295 strains), Acinetobacterhaemolyticus (3 strains), Acinetobacterlwoffii (16 strains), and unspeciated Acinetobacter (48 strains).

${ }^{b}$ Criteria as published by the CLSI [16].

During the observation period E. coli with an ESBL phenotype increased from $35.0 \%$ in 2005 to $52.4 \%$ in 2010 (p $<0.008$ ), Klebsiella spp. with an ESBL phenotype increased from $40.5 \%$ in 2005 to $43.8 \%$ in 2010, imipenem-non-susceptible Klebsiella spp.phenotype decreased from $8.1 \%$ in 2005 to $2.1 \%$ in 2010, ceftazidime-resistant Enterobacter spp.phenotype increased from $32.7 \%$ in 2005 to $46.4 \%$ in 2010, imipenem-non-susceptible Enterobacter spp. phenotype

Table 5 Comparison of the in vitro activities of selected antimicrobial agents tested against Enterobacterspp. ${ }^{\text {a }}$ (214 strains)

\begin{tabular}{llllc}
\hline Antimicrobial agent & MIC $_{\mathbf{5 0}}$ & $\mathbf{M I C}_{\mathbf{9 0}}$ Range & $\begin{array}{c}\text { \%susceptible / } \\
\text { resistant }^{\mathbf{b}}\end{array}$ \\
\hline Ceftriaxone & 0.25 & $>32$ & $\leq 0.25->32$ & $59.3 / 39.2$ \\
Ceftazidime & $\leq 1$ & $>16$ & $\leq 1->16$ & $62.6 / 34.5$ \\
Cefepime & $\leq 0.12$ & 8 & $\leq 0.12->16$ & $92.1 / 3.7$ \\
Piperacillin / tazobactam & 2 & $>64$ & $\leq 0.5->64$ & $73.8 / 26.1$ \\
Imipenem & 0.5 & 1 & $\leq 0.12-8$ & $98.6 / 0.0$ \\
Meropenem & $\leq 0.12$ & 0.12 & $\leq 0.12-4$ & $100.0 / 0.0$ \\
Ciprofloxacin & $\leq 0.03$ & $>4$ & $\leq 0.03->4$ & $85.0 / 14.0$ \\
Levofloxacin & $\leq 0.5$ & $>4$ & $\leq 0.5->4$ & $87.4 / 12.6$ \\
Gentamicin & $\leq 2$ & $>8$ & $\leq 2->8$ & $81.3 / 18.6$ \\
Amikacin & 2 & $>32$ & $\leq 4->32$ & $82.7 / 16.3$ \\
PolymyxinB & $\leq 0.5$ & $>4$ & $\leq 0.5->4$ & $-/$ - \\
Colistin & $\leq 0.5$ & $>4$ & $\leq 0.5->4$ & $-/-$ \\
\hline
\end{tabular}

a Includes Enterobacteraerogenes (38 strains), Enterobacteramnigenus (2 strains), Enterobactercancerogenus (1 strain), Enterobacter cloacae (161 strains), Enterobactergergoviae (6 strains), Enterobactersakazakii (4 strains), and unspeciated Enterobacter (2 strains).

${ }^{\mathrm{b}}$ Criteria as published by the CLSI [16]. 
Table 6 Yearly variation of main resistance phenotypes

\begin{tabular}{|c|c|c|c|c|c|c|}
\hline \multirow[t]{2}{*}{ Resistance phenotype } & \multicolumn{6}{|c|}{ Year of isolation (Total/Percentage) } \\
\hline & 2005 & 2006 & 2007 & 2008 & 2009 & 2010 \\
\hline E. coli ESBL phenotype $e^{\mathrm{a}, \mathrm{f}}$ & $36(35.0)$ & 26(37.7) & 29(38.7) & $42(40.0)$ & $45(54.2)$ & $67(52.4)$ \\
\hline Klebsiella spp. ESBL phenotype ${ }^{a}$ & $37(40.5)$ & 17(33.3) & $27(41.5)$ & $7.8(20.0)$ & 15(36.6) & $21(43.8)$ \\
\hline Imipenem-NSKlebsiella ${ }^{\mathrm{b}}$ & $7(8.1)$ & $2(2.0)$ & $3(4.6)$ & 0.00 & $2(4.9)$ & $1(2.1)$ \\
\hline Ceztazidime-R Enterobacter ${ }^{r}$ & $16(32.7)$ & $6(16.7)$ & 14(34.1) & $10(37.0)$ & $17(47.2)$ & $13(46.4)$ \\
\hline Imipenem-NS - Enterobacter $^{d}$ & $1(2.0)$ & 0.00 & $2(4.5)$ & $4(14.8)$ & 2(5.6) & $1(3.6)$ \\
\hline Imipenem-R Acinetobacter ${ }^{\mathrm{e} f}$ & $4(13.8)$ & 3(8.8) & $6(20.0)$ & $40(48.9)$ & $33(65.6)$ & $54(63.5)$ \\
\hline Imipenem-R P. aeruginosa ${ }^{\mathrm{e}}$ & 13(16.8) & $26(32.1)$ & 13(27.1) & $21(27.3)$ & $13(25.0)$ & $16(22.1)$ \\
\hline
\end{tabular}

${ }^{\text {a }}$ Defined as MIC $\geq 2 \mu \mathrm{g} / \mathrm{ml}$ for ceftazidime or ceftriaxone or aztreonam [CLSI, 2011].

${ }^{\mathrm{b}}$ Imipenem MIC of $\geq 2 \mu \mathrm{g} / \mathrm{ml}$ [CLSI, 2011].

c Ceftazidime MIC of $\geq 16 \mu \mathrm{g} / \mathrm{ml}$ [CLSI, 2011].

d Imipenem MIC of $\geq 2 \mu \mathrm{g} / \mathrm{ml}[\mathrm{CLSI}, 2011]$.

e Imipenem MIC of $\geq 8 \mu \mathrm{g} / \mathrm{ml}[\mathrm{CLSI}, 2011]$.

${ }^{f}$ Resistance trend over time $\mathrm{p}<0.05$.

increased from $2.0 \%$ in 2005 to $3.6 \%$ in 2010, imipenemresistant Acinetobacter spp. phenotype increased from $13.8 \%$ in 2005 to $63.5 \%$ in 2010 ( $\mathrm{p}<0.001)$, and the imipenem-resistant $P$. aeruginosa phenotype increased from $16.8 \%$ in 2005 to $22.1 \%$ in 2010 (Table 6).

\section{Summary and implications}

Overall the resistance pattern found in our analysis in $K$. pneumoniae, P. aeruginosa, Acinetobacter spp., and Enterobacter spp. is similar to that described in other Mexican and Latin American studies[19-24].

The similar susceptibility to ceftazidime and ceftriaxone in E.coli and Klebsiella spp. suggests that CTX-Mbeta-lactamases are present in our hospitals although not as widely disseminated as it occurred in the United States of America where susceptibility to ceftriaxone is much lower when compared to ceftazidime [25]. The production of CTX-M-type beta-lactamases in association with the production of other extended-spectrum-beta-lactamases have been reported in other areas in Mexico $[19,20]$. Certain resistant phenotypes encountered in this study are to be examined carefully, including the ESBL phenotype increase in $E$. coli, and the imipenem resistant phenotype increase in Acinetobacter spp.

The emergence of resistance to carbapenems and the lack of options for the treatment of $P$. aeruginosa infections with the exception of colistin and polymyxin $B$ are considerable $[25,26]$.

Some of the limitations of our report include the lack of resistance genotyping and of molecular strain typing.

The surveillance data presented by this study will help to guide clinicians in our hospitals in the selection of appropriate empiric antimicrobial treatment when confronted with gram-negative infections. Our findings can be used to monitor the evolution of bacterial resistance in other similar hospitals and will be helpful for the development of antibiotic stewardship programs.

\section{Competing interests}

The authors declare that they have no competing interests.

\section{Acknowledgments}

The data presented in this report is part of SENTRY Antimicrobial Surveillance Program (JMI Laboratories, North Liberty, IA, USA).

\section{Author details}

${ }^{1}$ Instituto de Patología Infecciosa y Experimental, Centro Universitario

Ciencias de la Salud, Universidad de Guadalajara, Calle Hospital 308, Colonia El Retiro, CP 44280, Guadalajara, Jalisco, Mexico. ${ }^{2}$ Infectología, Microbiología, Hospital Civil de Guadalajara, Fray Antonio Alcalde, Guadalajara, Mexico. ${ }^{3}$ Laboratorio de Microbiología, Hospital General de Durango, Secretaria de Salud, Durango, Mexico. ${ }^{4} \mathrm{JMI}$ Laboratories, North Liberty, IA, USA.

\section{Authors' contributions}

Conceived and designed the experiments: HSS, RMO, ERN, JCT. Performed the experiments: HSS, RMO, JCT, LSG, ERN. Acquisition and Analyzed the data: HSS, RMO, JCT, LSG, ERN, HRP, EGD, LP. Contributed reagents/materials/ analysis tools: HSS, RMO, JCT, LSG, ERN, HRP, EGD, LP. Wrote the paper: RMO, HSS, JCT, ERN. All authors read and approved the manuscript.

Received: 13 January 2012 Accepted: 7 June 2012

Published: 7 June 2012

\section{References}

1. Hidron Al, Edwards JR, Patel J, Horan TC, Sievert DM, Pollock DA, Fridkin SK: NHSN annual update: antimicrobial-resistant pathogens associated with healthcare-associated infections: annual summary of data reported to the National Healthcare Safety Network at the Centers for Disease Control and Prevention, 2006-2007. Infect control hosp epidemiol 2008, 29 (11):996-1011.

2. Peleg AY, Hooper DC: Hospital-acquired infections due to gram-negative bacteria. N Engl J Med 2010, 362(19):1804-1813.

3. Kallen AJ, Hidron Al, Patel J, Srinivasan A: Multidrug resistance among gram-negative pathogens that caused healthcare-associated infections reported to the National Healthcare Safety Network, 2006-2008. Infect Control Hosp Epidemiol 2010, 31(5):528-531.

4. Tumbarello M, Sanguinetti M, Montuori E, Trecarichi EM, Posteraro B, Fiori B, Citton R, D'Inzeo T, Fadda G, Cauda R, et al: Predictors of mortality in patients with bloodstream infections caused by extended-spectrumbeta-lactamase-producing Enterobacteriaceae: importance of inadequate initial antimicrobial treatment. Antimicrob Agents Chemother 2007, 51 (6):1987-1994

5. Giske CG, Monnet DL, Cars O, Carmeli Y: Clinical and economic impact of common multidrug-resistant gram-negative bacilli. Antimicrob Agents Chemother 2008, 52(3):813-821.

6. Fridkin SK, Edwards JR, Tenover FC, Gaynes RP, McGowan JE Jr: Antimicrobial resistance prevalence rates in hospital antibiograms reflect 
prevalence rates among pathogens associated with hospital-acquired infections. Clin Infect Dis 2001, 33(3):324-330.

7. Pakyz AL: The utility of hospital antibiograms as tools for guiding empiric therapy and tracking resistance. Insights from the Society of Infectious Diseases Pharmacists. Pharmacotherapy 2007, 27(9):1306-1312.

8. El-Azizi M, Mushtaq A, Drake C, Lawhorn J, Barenfanger J, Verhulst S, Khardori N: Evaluating antibiograms to monitor drug resistance. Emerg Infect Dis 2005, 11(8):1301-1302.

9. Funke G, Funke-Kissling P: Evaluation of the new VITEK 2 card for identification of clinically relevant gram-negative rods. $J$ Clin Microbiol 2004, 42(9):4067-4071.

10. Chatzigeorgiou KS, Sergentanis TN, Tsiodras S, Hamodrakas SJ, Bagos PG: Phoenix 100 versus Vitek 2 in the identification of gram-positive and gram-negative bacteria: a comprehensive meta-analysis. J Clin Microbiol 2011, 49(9):3284-3291.

11. CLSI: M07-A8: Methods for dilution antimicrobial susceptibility tests forbacteria that grow aerobically; approved standard. Wayne, PA: Clinical and Laboratory Standards Institute; 2009

12. CLSI: M100S21: Performance standards for antimicrobial susceptibility testing; twenty-first informational supplement. Wayne, PA: Clinical and Laboratory Standards Institute; 2011

13. Barry AL, Fuchs $P C$, Jones RN: Statistical criteria for selecting quality control limits for broth microdilution susceptibility tests with 39 different antimicrobial agents. Collaborative Antimicrobial Susceptibility Testing Group. Diagn Microbiol Infect Dis 1989, 12(5):413-420

14. Grundmann H, Livermore DM, Giske CG, Canton R, Rossolini GM, Campos J, Vatopoulos A, Gniadkowski M, Toth A, Pfeifer Y, et al: Carbapenem-nonsusceptible Enterobacteriaceae in Europe: conclusions from a meeting of national experts. Euro Surveill 2010, 15(46).

15. CLSI: M02-A11: Performance standards for antimicrobial disk susceptibility tests; approved standard-Eleventh edition. Wayne, PA: Clinical and Laboratory Standards Institute; 2012

16. CLSI: Performance Standards for antimicrobial susceptibility testing: Twentieth informational supplement (June 2010 update). Wayne, PA: Clinical and Laboratory Standards Institute; 2010

17. MacGowan A: Breakpoints for extended-spectrum beta-lactamaseproducing Enterobacteriacae: pharmacokinetic/pharmacodynamic considerations. Clin Microbiol Infect 2008, 14(Suppl 1):166-168.

18. Garza-Gonzalez E, Mendoza Ibarra SI, Llaca-Diaz JM, Gonzalez GM: Molecular characterization and antimicrobial susceptibility of extended-spectrum \{beta\}-lactamase-producing Enterobacteriaceae isolates at a tertiary-care centre in Monterrey, Mexico. J Med Microbiol 2011, 60(Pt 1):84-90.

19. Silva-Sanchez J, Garza-Ramos JU, Reyna-Flores F, Sanchez-Perez A, RojasMoreno T, Andrade-Almaraz V, Pastrana J, Castro-Romero Jl, Vinuesa P, Barrios $\mathrm{H}$, et al: Extended-spectrum beta-lactamase-producing enterobacteriaceae causing nosocomial infections in Mexico. A retrospective and multicenter study. Archives Med Res 2011, 42(2):156-162.

20. Morfin-Otero R, Rodriguez-Noriega E, Deshpande LM, Sader HS, Castanheira M: Dissemination of a bla(VIM-2)-carrying integron among Enterobacteriaceae species in Mexico: report from the SENTRY Antimicrobial Surveillance Program. Microb Drug Resist 2009, 15(1):33-35.

21. Quinteros M, Radice M, Gardella N, Rodriguez MM, Costa N, Korbenfeld D,

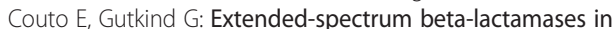
enterobacteriaceae in Buenos Aires, Argentina, public hospitals. Antimicrob Agents Chemother 2003, 47(9):2864-2867.

22. Villegas MV, Correa A, Perez F, Miranda MC, Zuluaga T, Quinn JP: Prevalence and characterization of extended-spectrum beta-lactamases in Klebsiella pneumoniae and Escherichia coli isolates from Colombian hospitals. Diagn Microbiol Infect Dis 2004, 49(3):217-222.

23. Sader HS, Castanheira M, Mendes RE, Toleman M, Walsh TR, Jones RN: Dissemination and diversity of metallo-beta-lactamases in Latin America: report from the SENTRY Antimicrobial Surveillance Program. Int $J$ Antimicrob Agents 2005, 25(1):57-61.

24. Castanheira M, Sader HS, Jones RN: Antimicrobial susceptibility patterns of KPC-producing or CTX-M-producing Enterobacteriaceae. Microb Drug Resist 2010, 16(1):61-65.

25. Nordmann P, Cuzon G, Naas T: The real threat of Klebsiella pneumoniae carbapenemase-producing bacteria. Lancet Infect Dis 2009, 9(4):228-236.

26. Tam VH, Chang KT, Abdelraouf K, Brioso CG, Ameka M, McCaskey LA, Weston JS, Caeiro JP, Garey KW: Prevalence, resistance mechanisms, and susceptibility of multidrug-resistant bloodstream isolates of
Pseudomonas aeruginosa. Antimicrob Agents Chemother 2010, 54(3):11601164

doi:10.1186/1756-0500-5-277

Cite this article as: Morfin-Otero et al:: Resistance trends in gramnegative bacteria: surveillance results from two Mexican hospitals, 2005-2010. BMC Research Notes 2012 5:277.

\section{Submit your next manuscript to BioMed Central and take full advantage of:}

- Convenient online submission

- Thorough peer review

- No space constraints or color figure charges

- Immediate publication on acceptance

- Inclusion in PubMed, CAS, Scopus and Google Scholar

- Research which is freely available for redistribution 